\title{
46,XX DSD and Antley-Bixler syndrome due to novel mutations in the cytochrome P450 oxidoreductase gene
}

\author{
DDS 46,XX e síndrome de Antley-Bixler causada por novas \\ mutações no gene da enzima P450 oxidorredutase
}

\begin{abstract}
Guilherme Guaragna-Filho 1,2, Carla Cristina Telles de Sousa Castro 1,2, Rodrigo Ribeiro De Carvalho ${ }^{3}$, Fernanda Borchers Coeli ${ }^{3}$, Lúcio Fábio Caldas Ferraz ${ }^{3}$, Reginaldo José Petroli3 ${ }^{3}$ Maricilda Palandi De Mello ${ }^{3}$, Letícia Esposito Sewaybricker ${ }^{1,2}$, Sofia Helena Valente Lemos-Marini', Lilia Freire Rodrigues D'Souza-Li', Márcio Lopes Miranda ${ }^{4}$, Andréa Trevas Maciel-Guerra ${ }^{2,5}$, Gil Guerra-Junior ${ }^{1,2}$
\end{abstract}

${ }^{1}$ Departamento de Pediatria, Unidade de Endocrinologia Pediátrica, Faculdade de Ciências Médicas, Universidade Estadual de Campinas (FCMUnicamp), Campinas, SP, Brazil ${ }^{2}$ Grupo Interdisciplinar de Estudos da Determinação e Diferenciação do Sexo (GIEDDS), FCMUnicamp, Campinas, SP, Brazil ${ }^{3}$ Centro de Biologia Molecular e Engenharia Genética (CBMEG), Unicamp, Campinas, SP, Brazil ${ }^{4}$ Departamento de Cirurgia, Disciplina de Cirurgia Pediátrica, FCM-Unicamp, Campinas, SP, Brazil

${ }^{5}$ Departamento de Genética Médica, FCM-Unicamp,

Campinas, SP, Brazil

Correspondence to:

Gil Guerra-Junior

Departamento de Pediatria

FCM-Unicamp

13083-100 - Campinas, SP, Brazil

gilguer@fcm.unicamp.br

Received on July/31/2012 Accepted on Oct/29/2012

\section{SUMMARY}

Deficiency of the enzyme P450 oxidoreductase is a rare form of congenital adrenal hyperplasia with characteristics of combined and partial impairments in steroidogenic enzyme activities, as P450 oxidoreductase transfers electrons to CYP21A2, CYP17A1, and CYP19A1. It results in disorders of sex development and skeletal malformations similar to Antley-Bixley syndrome. We report the case of a 9-year-old girl who was born with virilized genitalia (Prader stage V), absence of palpable gonads, 46,XX karyotype, and hypergonadotropic hypogonadism. During the first year of life, ovarian cyst, partial adrenal insufficiency, and osteoarticular changes, such as mild craniosynostosis, carpal and tarsal synostosis, and limited forearm pronosupination were observed. Her mother presented severe virilization during pregnancy. The molecular analysis of P450 oxidoreductase gene revealed compound heterozygosis for the nonsense p.Arg223*, and the novel missense p.Met408Lys, inherited from the father and the mother, respectively. Arq Bras Endocrinol Metab. 2012;56(8):578-85

\begin{abstract}
SUMÁRIO
A deficiência da enzima P450 oxidorredutase é uma forma rara de hiperplasia congênita da adrenal com características de inibição combinada e parcial de enzimas esteroidogênicas, pois a enzima P450 oxidorredutase participa da transferência de elétrons para as enzimas CYP21A2, CYP17A1 e CYP19A1. Essa deficiência causa um distúrbio do desenvolvimento do sexo e alterações esqueléticas semelhantes às da síndrome de Antley-Bixley. Relatamos o caso de uma menina, atualmente com 9 anos de idade, que apresentava ao nascimento genitais virilizados (Prader 5) sem gônadas palpáveis, com cariótipo $46, X X$ e hipogonadismo hipergonadotrófico. No primeiro ano de vida, foram observados cisto ovariano, insuficiência adrenal parcial e alterações osteoarticulares como leve craniossinostose, sinostose carpal e tarsal e limitação de pronossupinação dos membros superiores. Sua mãe apresentou intensa virilização durante a gestação. 0 estudo molecular do gene $\mathrm{P} 450$ oxidorredutase revelou a heterozigose composta das mutações nonsense p.Arg223* e da missense nova p.Met408Lys, herdadas do pai e da mãe, respectivamente. Arq Bras Endocrinol Metab. 2012;56(8):578-85
\end{abstract}

\section{INTRODUCTION}

$\mathrm{C}$ ytochrome P450 monooxygenases are enzymes that catalyze the oxidation of several organic compounds. Two biochemical classes of P450 enzymes have been distinguished in the human genome.
In the adrenal glands, type I enzymes, located in the mitochondria, receive electrons from reduced nicotinamide adenine dinucleotide (NADPH) mediated by a flavoprotein and an iron-sulfur protein called, respectively, adrenodoxin reductase and adrenodoxin; in 
turn, type II enzymes are expressed in the endoplasmic reticulum and receive electrons from NADPH via a single $\mathrm{P} 450$ flavoprotein. Cytochrome $\mathrm{P} 450$ oxidoreductase (OMIM * 124015 ; POR) is the only electron donor flavoprotein for the cytochrome $\mathrm{P} 450$ type II enzyme complex, including the steroidogenic 17 $\alpha$-hydroxylase/17,20-lyase (CYP17Al), 21-hydroxylase (CYP21A2), and aromatase (CYP19A1) (1). $\mathrm{POR}$ is an $82-\mathrm{kDa}$ membrane-associated protein encoded by the POR gene, which is formed by 15 exons spanning $32 \mathrm{~kb}$ on the $7 \mathrm{ql} 1.2$ chromosomal band (2). Association with the allosteric cytochrome b5 can enhance POR activity, as demonstrated by 17,20-lyase reactions and some hepatic P450 enzymes (3).

POR deficiency (OMIM \#613571; PORD) is a rare and complex form of congenital adrenal hyperplasia that results from partial and combined impairment of steroidogenic enzymes. This autosomal recessive disorder was described for the first time in 2004, when mutations in POR encoding gene were identified $(4,5)$. PORD has a wide spectrum of clinical signs and symptoms, including partial and combined enzymatic adrenal dysfunction associated with disorders of sex development (DSD) in 46,XX and 46,XY individuals, and skeletal abnormalities of Antley-Bixler syndrome (OMIN \#201750) (6). Maternal hyperandrogenism and virilization during pregnancy can also be observed. Skeletal malformations observed in many, but not all, patients with PORD are considered to be due to impairment of enzyme activities involved in sterol synthesis, such as $14 \alpha$-lanosterol demethylase (CYP51Al) and squalene epoxidase, disruption of retinoic acid metabolism catalyzed by CYP26 isozymes $(6,7)$, and hepatic drug metabolism (8).

To date, the public and private Human Gene Mutation Databases report, respectively, 57 and 79 mutations in the POR gene (9). Most of them are missense, followed by nonsense, splicing, and a couple of deletions. Depending on the type of mutation and its location within the POR gene, it may reduce CYP17Al, CYP21A2, CYP19Al activities differently. Therefore, POR variants must be studied separately for each potential P450 target enzyme (10).

Here, we report a 46,XX patient with PORD and manifestations of the Antley-Bixler syndrome in whom POR gene analysis revealed compound heterozygosis for the nonsense p.Arg223* and the novel missense p.Met408Lys, inherited from the father and the mother, respectively.

\section{CASE REPORT}

A girl, who was the third child of a healthy mother, was born at term by vaginal delivery. At birth, she weighed $2,830 \mathrm{~g}$ and her height was $48 \mathrm{~cm}$, with head circumference of $32.5 \mathrm{~cm}$. Due to the virilized genital appearance, she was assigned as a male. The mother, who denied the use of drugs during gestation, reported severe virilization with hirsutism, clitoromegaly, and voice deepening (Figure 1A). All these signs regressed after delivery. She also reported two previous uneventful gestations: a normal girl from her first marriage and a healthy boy.

At the first appointment in our service, the patient was 8 months old with male assignment. General physical examination indicated virilized genitalia with Prader stage V and $2.3-\mathrm{cm}$ phallus, without palpable gonads; balanic urethral opening and complete fusion
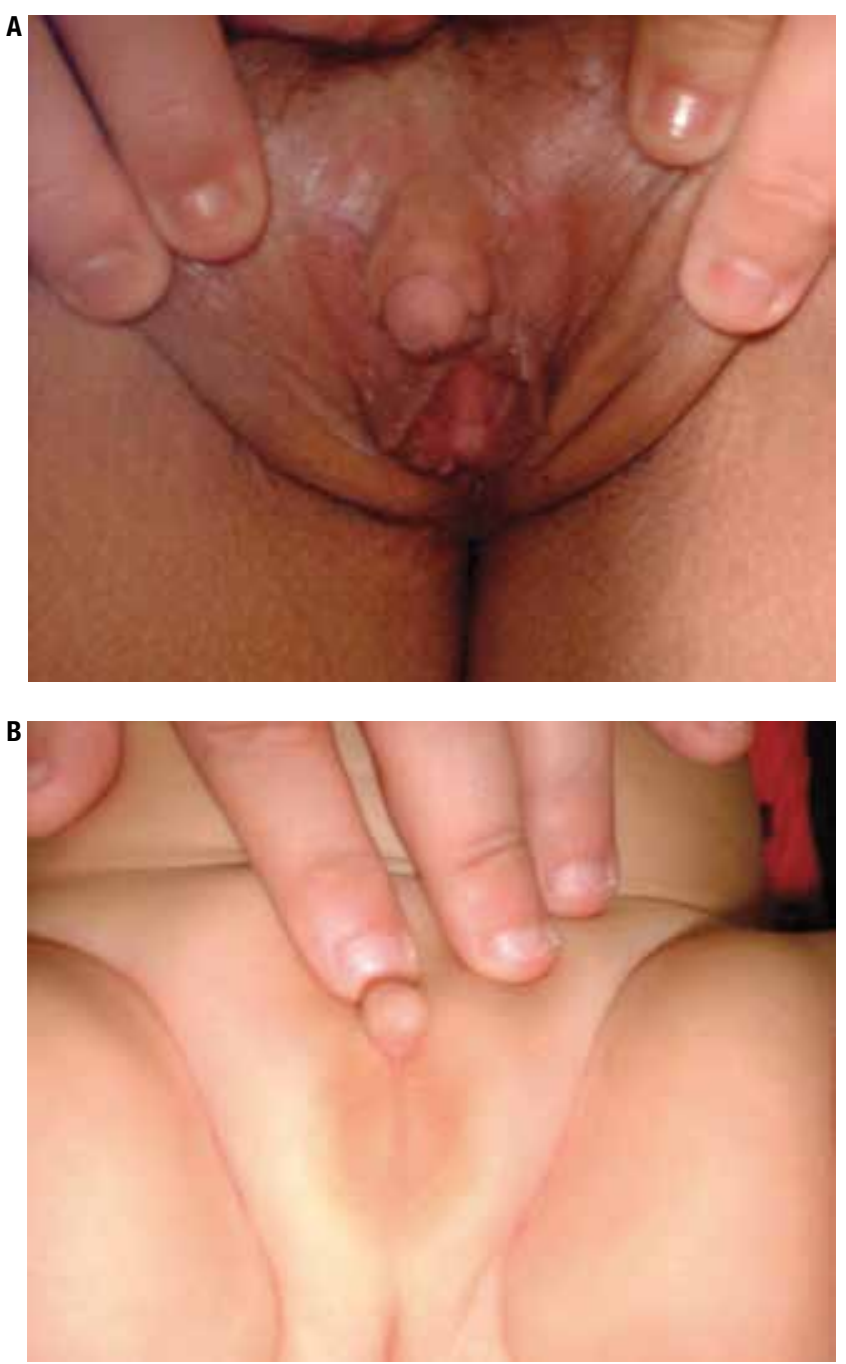

Figure 1. Mother's (A) and child's (B) external genitalia 8 months after delivery. 
of labioscrotal folds, which were not pigmented, were also observed (Figure 1B). No other dysmorphic signs or physical alterations were observed. The mother reported that the phallus length had diminished since birth. Initial cytogenetic investigation revealed a 46,XX karyotype in 30 metaphases analyzed. A $1.1-\mathrm{cm}^{3}$ uterus and gonads with typical ovarian shape were observed upon pelvic ultrasonography, with an anechoic homogeneous image in the left adnexial region, suggestive of a simple ovarian cyst.

The moderate increase of $17-\mathrm{OH}$ progesterone level and low androgen (DHEA, androstenedione and testosterone) levels did not confirm either 21-hydroxylase or $11 \beta$-hydroxylase deficiencies (Table 1). Therefore, the first hypothesis considered for the diagnosis was the CYP19 deficiency, based on the severe virilization of the mother during pregnancy. However, the CYP19 gene analysis did not confirm such diagnosis. Although the etiology of the clinical signs remained undefined, when the patient was 18 months old, it was decided to reassign the sex from male to female, with the agreement of the family, and feminizing introitoplasty was performed. Gonadal biopsy confirmed the presence of two normal ovaries.

Almost one year after the first appointment, mutations in the POR gene sequence were investigated. The c.667C $>\mathrm{T}$ and c.1223T $>\mathrm{A}$ nucleotide changes located in exon 6 and in exon 10, respectively, were identified (Figure 2). The c.667C $>\mathrm{T}$ nucleotide change affects codon 223 , causing a CGA $>$ TGA substitution that forms a premature stop codon; whereas the c.1223T $>\mathrm{A}$ nucleotide change leads to a change in residue 408 from a methionine (ATG) to a lysine (AAG). Sequencing of the POR gene of her parents indicated that the
p.Arg223* and p.Met408Lys mutations were inherited from the father and the mother, respectively. The biological importance of p.Met408Lys change in the structure of the enzyme was investigated by modeling the mutant enzyme and comparing it to its wild type.

Laboratory follow-up from 8 to 105 months is detailed in table 1 . She had never presented any abnormalities related to neurological and growth development until the age of 64 months, when X-ray examinations demonstrated discrete reduction in cephalic diameters,

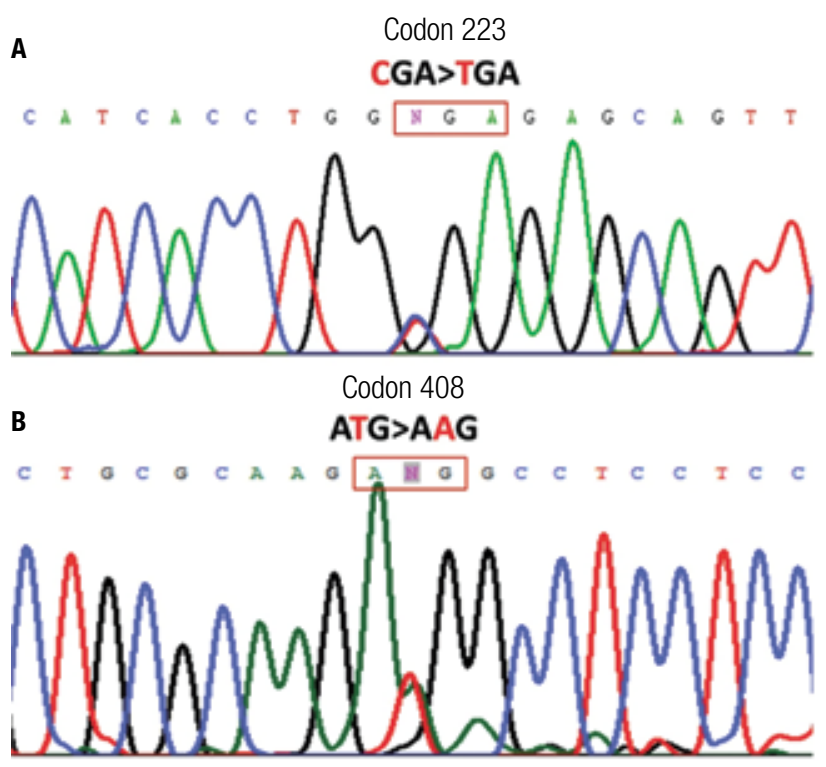

Figure 2. Partial electropherograms of $P O R$ gene sequencing of a patient with POR deficiency. A) The c.667C $>$ T nucleotide change in exon 6 causes the CGA>TGA substitution at codon 223; an arginine is replaced by a stop codon, representing the null mutation p.Arg223* . B) The c. $1223 \mathrm{~T}>\mathrm{A}$ nucleotide change located in exon 10 causes the ATG $>A A G$ substitution in codon 408, leading to the missense p.Met408Lys. The p.Arg223* and p.Met408Lys mutations were inherited from the father and the mother, respectively.

Table 1. Hormonal profile of the patient with POR deficiency during the first 105 months of life

\begin{tabular}{|c|c|c|c|c|c|c|c|}
\hline & \multicolumn{7}{|c|}{ Age (months) } \\
\hline & \multirow{2}{*}{8} & \multirow{2}{*}{18} & \multicolumn{3}{|c|}{48} & \multirow{2}{*}{67} & \multirow{2}{*}{105} \\
\hline & & & Basal & Post ACTH & Post hCG & & \\
\hline $\mathrm{FSH}(\mathrm{IU} / \mathrm{L})^{* 1}$ & 23.3 & 10.4 & 1.3 & - & - & 1.2 & 1.3 \\
\hline $\mathrm{LH}(\mathrm{IU} / \mathrm{L})^{* 2}$ & 13.5 & 0.5 & $<0.1$ & - & - & $<0.1$ & $<0.1$ \\
\hline ACTH $(p g / m L)^{\star 3}$ & 20.3 & 26.8 & 20.9 & - & - & 35.3 & 42.9 \\
\hline Cortisol $(\mu \mathrm{g} / \mathrm{dL})^{\# 4}$ & 9.0 & 8.8 & 7.8 & 14.3 & - & 9.1 & 8.9 \\
\hline 17-OH progesterone $(\mathrm{ng} / \mathrm{mL})^{\# 5}$ & 11.6 & 2.9 & 3.8 & 13.3 & - & 6.6 & 5.0 \\
\hline DHEA (ng/mL) $)^{\# 6}$ & 0.6 & 0.5 & 1.0 & 1.1 & - & 1.1 & 1.4 \\
\hline Androstenedione $(\mathrm{ng} / \mathrm{mL})^{\star} 7$ & 0.2 & 0.1 & 0.1 & 0.5 & - & 0.1 & 0.2 \\
\hline Testosterone $(\mathrm{ng} / \mathrm{mL})^{* 8}$ & $<0.02$ & $<0.02$ & $<0.02$ & - & 0.09 & $<0.02$ & $<0.02$ \\
\hline
\end{tabular}

* Electrochemiluminescence assay; ${ }^{\text { radioimmunoassay; normal range (pre-pubertal girls): }{ }^{1}<0.1-3.8 ;{ }^{2}<0.1-1.4 ;{ }^{3}<46 ;{ }^{4} 5.0-22.0 ;{ }^{5} 0.07-1.5 ;{ }^{6}<2.5 ;{ }^{7} 0.05-0.5 ;{ }^{8}<0.2 .}$ 
"hammered silver" appearance usually associated to craniosynostosis (Figure 3A), and carpal and tarsal synostoses (Figures $3 \mathrm{~B}$ and $3 \mathrm{C}$ ). When she was 7 years old, she complained of limited movement of the arms; radiological investigation was normal, despite limited pronosupination. The score of osteoarticular anomalies was 5 , according to Krone and cols. (11).

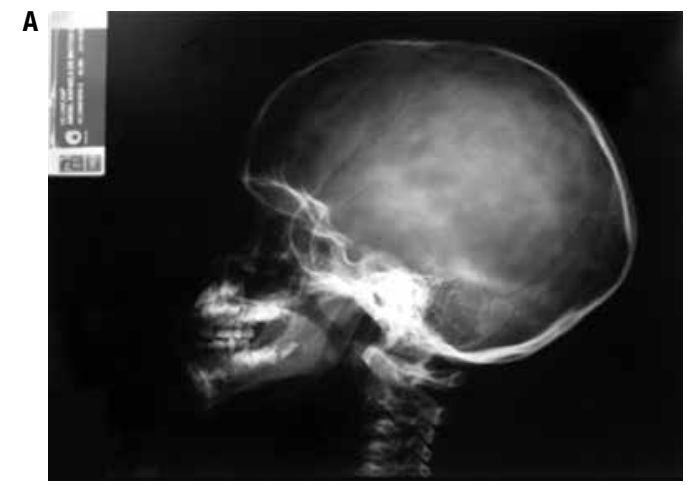

B
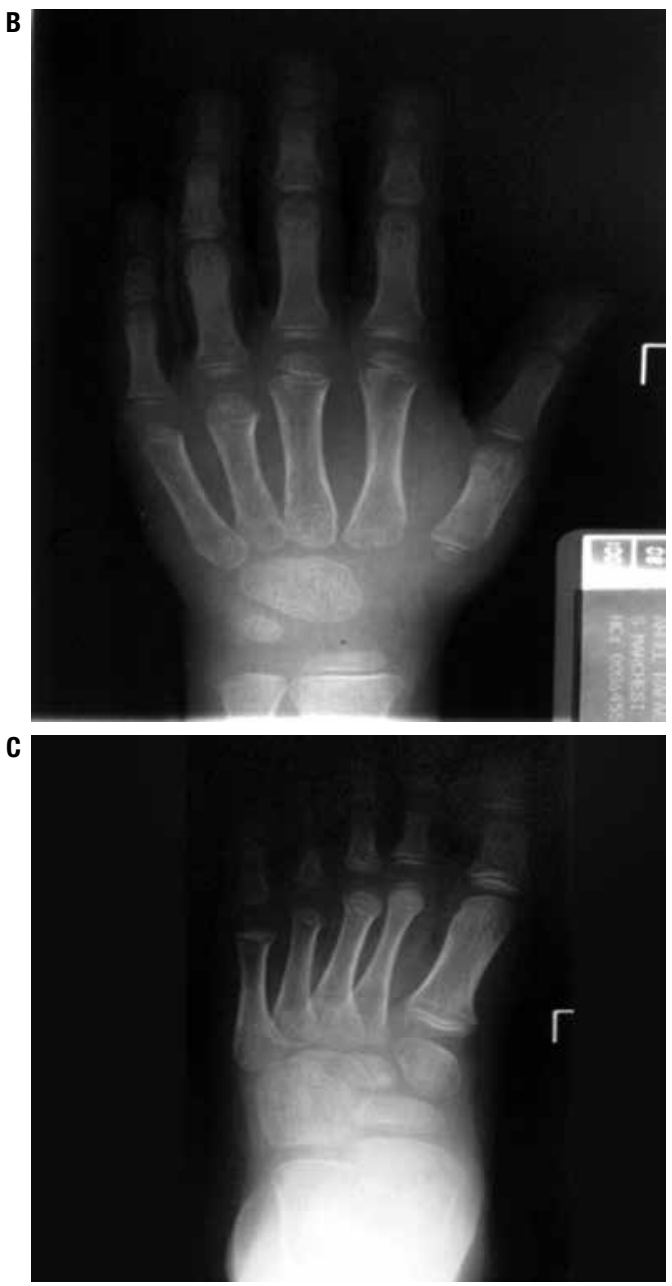

Figure 3. Radiographs of the skull (A), left hand (B) and left foot (C) of the patient with POR deficiency, showing a shortened diameter of the head and hammered-silver appearance (A), carpal synostosis (B), and tarsal synostosis (C).
She had never required hydrocortisone replacement therapy, except before and after the two additional surgical procedures that she had been submitted to: vaginal dilation at 5 years of age due to vaginal stenosis and endometritis, and clitoroplasty at the age of 6 . She is now 9 years old, her weight is $31 \mathrm{~kg}(\mathrm{z}=0.32)$, height $133 \mathrm{~cm}(\mathrm{z}=-0.02$, within her target height $)$, and head circumference $51 \mathrm{~cm}$ (slightly below the mean) (Figure 4A); her bone age is compatible with chronological age, she has normal female genitalia with no signs of puberty (Figure 4B), and she takes no medications.

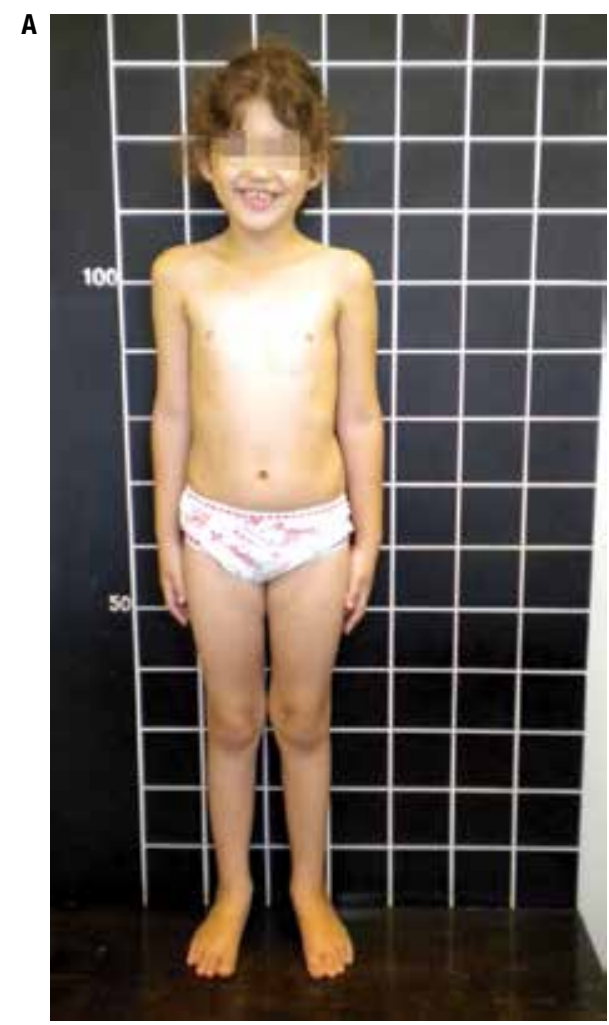

B

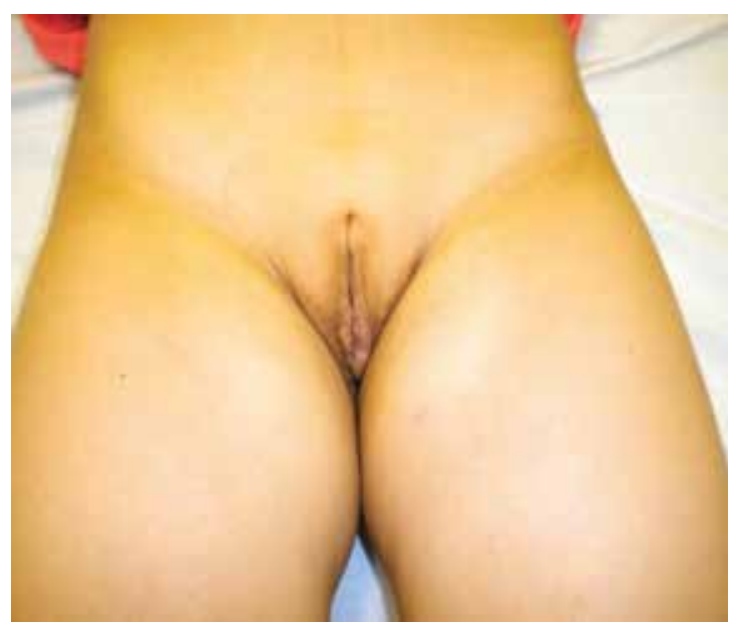

Figure 4. Patient with POR deficiency at 9 years old $(\mathbf{A})$ and her external genitalia after genitoplasty (B). 


\section{MATERIALS AND METHODS}

Samples of peripheral blood leukocytes were obtained and genomic DNA extraction was performed by standard techniques (12). The 10 exons of CYP19A1 gene and the 15 exons of the POR gene, as well as exon-intron junctions were amplified by PCR in different fragments. Before sequencing, each PCR fragment was purified using the Wizard ${ }^{\circledR}$ SV Gel and PCR clean-up system (Promega, Madison, WI, USA). Further direct sequencing using ABI PRISM Big Dye Terminator v3.1 Cycle Sequencing Kit (ABI PRISM/PE Biosystems, Foster City, CA, USA) was carried out in separated reactions using sense and antisense primers. The sequences were obtained in an automatic sequencer ABI PRISM 3130 DNA Analyzer (ABI PRISM/PE Biosystems). Free software Chromas Pro v.1.5 and CLC Sequence Viewer v.6.6.2 were used to analyze and compare sequences with the published CYP19AI and POR sequences at Ensembl database (ENSG00000137869 and ENSG00000127948, respectively, www.ensembl.org). The structure used in modeling analyses for p.Met408Lys mutation was the crystallographically-resolved POR structure PDB ID: 3QE2 (13). Molecular modeling was performed using MODELLER web server software. Modelled images were examined and edited using a free version of Py$\mathrm{MOL}^{\circledR}$ and internal contacts were investigated using the Millennium STING (CNPTIA-Embrapa, Brazil).

\section{DISCUSSION}

A case of PORD caused by the compound heterozygosis for p.Arg223* and p.Met408Lys is reported. The p.Arg223* creates a premature stop codon and may probably activate nonsense mRNA decay before translation. This mutation was described recently in a patient who carried p.Arg223* in compound heterozygosis with p.Arg287Pro, which is considered the most common POR mutation in Caucasians (14). The p.Met408Lys is described here for the first time. It is a non-conservative substitution, since it replaces the neutral nonpolar hydrophobic methionine residue by the basic polar hydrophilic lysine residue at codon 408. Residue 408 is located at the boundary of flavin adenine dinucleotide (FAD) domain and a hinge region that links FAD domain to flavin mononucleotide (FMN) domain (Figure 5A). The alignment of modeled wild-type and mutated POR structures did not show differences in protein folding. However, divergences in two disordered regions can be observed in the hinges. In the wild-type protein, the Met 408 residue is in contact with Leu404 and Leu418 (Figure 5B). The methionine-to-lysine substitution creates novel internal contacts with neighboring residues, such as L389 and W422 (Figure 5C). Those four residues, in turn, establish additional contacts with other residues and with the p.Met408Lys mutation (Figure 5D-K). If such modifications cause disturbances in enzymatic activity should be further investigated. However some possibilities can be considered based on data in the literature.
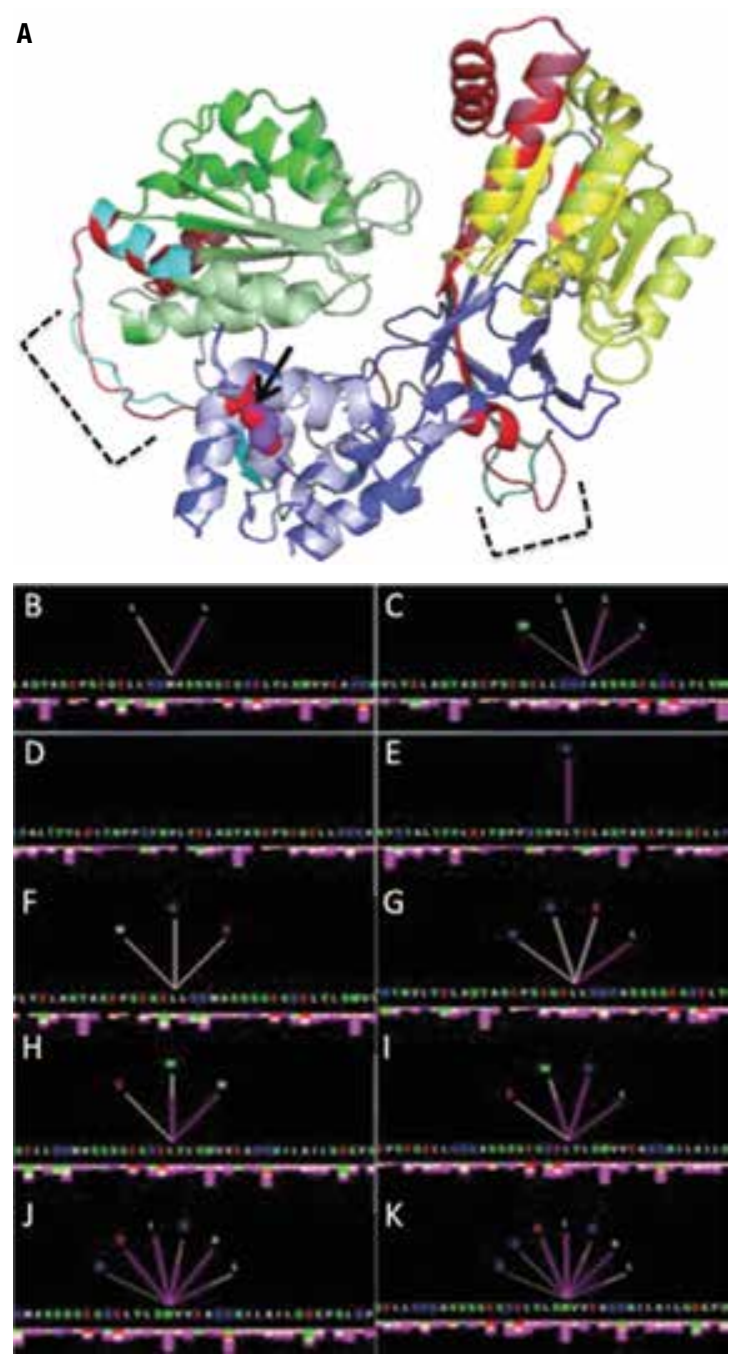

Figure 5. Alignment of structures of wild-type and p.Met408Lys proteins (A); FMN domain is denoted in green (dark green = wild-type; light green = mutant); FAD domain is denoted in blue (dark blue = wild-type; light blue = mutant); and NADPH domain is denoted in yellowish tones (yellow = wildtype; greenish-yellow = mutant); red and cyan represent the hinge regions of the wild-type and mutant proteins, respectively; black arrow points to the normal Met408 (purple) and mutated Lys408 (red) residues; dashed lines delimit hinge divergences. Internal contacts for residues 408, 389, 404, 418 , and 422 are shown in the left (B, D, F, H, J) and in the right (C, E, G, $\mathbf{I}, \mathbf{K})$ for the wild-type and mutant proteins, respectively. The color of lines and bars below each amino acid represents different chemical interactions: hydrophobic (pink), hydrogen bond (rose), aromatic stacking (grey). 
Hamdane and cols. (15) demonstrated that the hinge region facilitates electron transfer from FAD to FMN by properly aligning and orienting the two flavin domains. They conclude that electron flow from FAD to FMN and from FMN to CYPs may be regulated by adjusting the distance and orientation of the two flavin cofactors. Furthermore, their report provided evidence that POR enzyme may undergo conformational changes for proper electron transfer to its redox partners. As p.Met408Lys mutation causes disturbances in the conformational arrangement of the hinge and establishes novel local interactions, it may alter enzymatic activity by modifying the conformation of the hinge region, so that the flexibility necessary to promote electron transfer is impaired (16).

The reported patient did not present neonatal signs of skeletal malformations; however, during childhood, she developed a few osteoarticular abnormalities, such as carpal and tarsal synostosis, reduced skull diameter and "hammered-silver" appearance (suggestive of craniosynostosis), and limited forearm pronosupination, indicating that periodic clinical and image evaluations were necessary $(6,10,11,17,18)$. Considering that p.Arg223* is a null allele in the compound heterozygosis with p.Met408Lys, it can be inferred that the residual activity of p.Met408Lys missense carrying allele is defining the patient's phenotype. Different from the most studied p.Ala287Pro and p.Arg457His mutations, which have been frequently observed in Japanese patients and are related to severe inborn skeletal malformations $(6,10,18)$, p.Met408Lys seems to be more deleterious to POR activity related to the androgenic pathway than to skeletal development, since the patient presented severe virilizition and no signs of skeletal malformations at birth. Krone and cols. (11) proposed a score for the evaluation of osteoarticular manifestations in PORD patients. According to this methodology, total malformation score (TMS) can vary from 0 to 16. Following this score method, our patient presented TMS of 5 , which refers to a moderate grade malformations.

PORD may lead to genital ambiguity in both sexes: boys may present undervirilization due to inadequate testosterone production resulting from CYP17Al impairment, and genital ambiguity in girls may be the result of more complex mechanisms, mainly those from defective CYP19Al activity with excessive androgen production and activation of the alternative SRD5Al and AKRIC pathways, as well as direct conversion of $17 \mathrm{OH}$-progesterone to dihydrotestosterone (DHT) $(2,11,19,20)$. Probably, only CYP19Al was affected in this case, leading severe virilization of both mother and child with low testosterone and high $17 \mathrm{OH}$-progesterone levels.

The literature is still controversial regarding the need for daily glucocorticoid replacement in PORD. However, most authors agree with drug administration only in case of moderate to severe stress, especially for those patients who do not present adequate cortisol response to ACTH stimulus, as was the case of our patient (11,18,21-25). Therefore, glucocorticoid was only administrated upon stress situations. Mineralocorticoid reposition is not necessary, although deficient POR activity may affect CYP21A2 catalyzed reactions $(11,24)$.

PORD deficiency differs from other congenital adrenal hyperplasias because it affects multiple enzymes, leading them to partial activities and resulting in a variable hormonal profile. Upon CYP21A2 activity, there are moderately elevated basal and ACTH-stimulated 17OH-progesterone levels. However, dihydroepiandrosterone (DHEA), DHEA-sulphate and androstenedione levels are generally low or normal due to the low 17,20-lyase activity of CYP17Al. This hormonal profile, which is usually observed in patients with PORD, including this patient, indicates that the 21-hydroxylation activity by CYP21A2 is as diminished as the 17-hydroxylation activity by CYP17Al $(4,6,18,25)$.

Puberty is another important aspect to be considered; however, knowledge regarding its evolution and the hormonal profile of patients with PORD is not totally available yet. It seems that male patients spontaneously begin and progress to puberty more easily than female patients, although both sexes present different levels of hypergonadotropic hypogonadism in all reported cases $(4,14,17,18,24)$.

Similar to the patient reported here, the great majority of female patients in pubertal age and infants in minipuberty reported in the literature present ovarian cysts and hypergonadotropic hypogonadism $(14,17,18,24)$. Ovarian cysts are a common finding in females affected by steroidogenic disorders, have been reported in deficiencies of CYP21A2 (26), CYP17Al (27), STAR (28), CYP19Al (29) and, recently, in POR deficiency $(14,18,30)$. A unique mechanism driving ovarian cyst development in females affected by PORD, in addition to high gonadotropins resulting from estrogen deficiency, might be the disruptive impact of mutant POR on sterol synthesis and metabolism. CYP51Al requires electron transfer from POR for catalytic activity, and 
catalyzes the conversion from lanosterol to meiosis-activating sterols. Follicular fluid meiosis-activating sterols have been shown to be crucial to resume oocyte meiosis at puberty, and to support oocyte maturation (31). It is suggested in the literature that hormonal replacement could ameliorate the presence of polycystic ovaries $(14,18)$. Although our patient still have not shown any pubertal signs, she presented elevated gonadotropin levels and a suggestive image of an ovarian cyst upon ultrasonography in the first months of life.

Concluding, we present a case report on a girl with PORD who is compound heterozygous for the nonsense p.Arg223* and the novel missense p.Met408Lys mutations associated with severe maternal virilization, 46,XX DSD, partial glucocorticoid insufficiency, hypergonadotropic hypogonadism, and ovarian cysts during the first year of life, as well as late onset features of Antley-Bixler syndrome.

Disclosure: no potential conflict of interest relevant to this article was reported.

\section{REFERENCES}

1. Miller WL. Minireview: regulation of steroidogenesis by electron transfer. Endocrinology. 2005;146:2544-50.

2. Scott RR, Gomes LG, Huang N, Van Vliet G, Miller WL. Apparent manifesting heterozygosity in P450 oxidoreductase deficiency and its effect on coexisting 21-hydroxylase deficiency. J Clin Endocrinol Metab. 2007;92:2318-22.

3. Auchus RJ, Lee TC, Miller WL. Cytochrome b5 augments the 17,20-lyase activity of human P450c17 without direct electron transfer. J Biol Chem. 1998;273:3158-65.

4. Flück CE, Tajima T, Pandey AV, Arlt W, Okuhara $K$, Verge $C F$, et al. Mutant P450 oxidoreductase causes disordered steroidogenesis with and without Antley-Bixler syndrome. Nat Genet. 2004;36:228-30.

5. Arlt W, Walker EA, Draper N, Ivison HE, Ride JP, Hammer F, et al. Congenital adrenal hyperplasia caused by mutant P450 oxidoreductase and human androgen synthesis: analytical study. Lancet. 2004;363:2128-35.

6. Scott RR, Miller WL. Genetic and clinical features of P450 oxidoreductase deficiency. Horm Res. 2008;69:266-75.

7. Polusani SR, Kar R, Riquelme MA, Masters BS, Panda SP. Regulation of gap junction function and connexin 43 expression by cytochrome P450 oxidoreductase (CYPOR). Biochem Biophys Res Commun. 2011;411:490-5.

8. Tomalik-Scharte D, Maiter D, Kirchheiner J, Ivison HE, Fuhr U, Arlt W. Impaired hepatic drug and steroid metabolism in congenital adrenal hyperplasia due to P450 oxidoreductase deficiency. Eur J Endocrinol. 2010;163:919-24.

9. Human Gene Mutation Database. Available at: http://www.hgmd. cf.ac.uk/ac/index.php. Accessed on: Nov 17, 2012.

10. Flück $C E$, Pandey AV. Clinical and biochemical consequences of P450 oxidoreductase deficiency. Endocr Dev. 2011;20:63-79.

11. Krone N, Reisch N, Idkowiak J, Dhir V, Ivison HE, Hughes BA, et al. Genotype-phenotype analysis in congenital adrenal hyperplasia due to P450 oxidoreductase deficiency. J Clin Endocrinol Metab. 2012;97:E257-67.

12. Sambrook J, Fristsch EF, ManiatisTE. Molecular Cloning: a laboratory manual. Cold Spring Harbor, NY: Cold Spring Harbor Laboratory Press; 1989.

13. Xia C, Panda SP, Marohnic CC, Martásek P, Masters BS, Kim JJ. Structural basis for human NADPH-cytochrome P450 oxidoreductase deficiency. Proc Natl Acad Sci U S A. 2011;108:13486-91.

14. Idkowiak J, O'Riordan S, Reisch N, Malunowicz EM, Collins F, Kerstens MN, et al. Pubertal presentation in seven patients with congenital adrenal hyperplasia due to $\mathrm{P} 450$ oxidoreductase deficiency. J Clin Endocrinol Metab. 2011;96(3):E453-62.

15. Hamdane D, Xia C, Im SC, Zhang H, Kim JJ, Waskell L. Structure and function of an NADPH-cytochrome P450 oxidoreductase in an open conformation capable of reducing cytochrome P450. J Biol Chem. 2009;284(17):11374-84.

16. Xia C, Hamdane D, Shen AL, Choi V, Kasper CB, Pearl NM, et al. Conformational changes of NADPH-cytochrome P450 oxidoreductase are essential for catalysis and cofactor binding. J Biol Chem. 2011;286:16246-60.

17. Herkert JC, Blaauwwiekel EE, Hoek A, Veenstra-Knol HE, Kema $I P$, Arlt $W$, et al. A rare cause of congenital adrenal hyperplasia: Antley-Bixler syndrome due to POR deficiency. Neth J Med. 2011;69:281-3.

18. Fukami M, HasegawaT, Horikawa R, Ohashi T, Nishimura G, Homma K, et al. Cytochrome P450 oxidoreductase deficiency in three patients initially regarded as having 21-hydroxylase deficiency and/or aromatase deficiency: diagnostic value of urine steroid hormone analysis. Pediatr Res. 2006;59:276-80.

19. Flück $C E$, Miller WL. P450 oxidoreductase deficiency: a new form of congenital adrenal hyperplasia. Curr Opin Pediatr. 2006;18:435-41.

20. Homma K, Hasegawa T, Nagai T, Adachi M, Horikawa R, Fujiwara I, et al. Urine steroid hormone profile analysis in cytochrome P450 oxidoreductase deficiency: implication for the backdoor pathway to dihydrotestosterone. J Clin Endocrinol Metab. 2006;91:2643-9.

21. But WM, Lo IF, Shek CC, Tse WY, Lam ST. Ambiguous genitalia, impaired steroidogenesis, and Antley-Bixler syndrome in a patient with P450 oxidoreductase deficiency. Hong Kong Med J. 2010;16:59-62.

22. lijima S, Ohishi A, Ohzeki T. Cytochrome P450 oxidoreductase deficiency with Antley-Bixler syndrome: steroidogenic capacities. J Pediatr Endocrinol Metab. 2009;22:469-75.

23. Ko JM, Cheon CK, Kim GH, Yoo HW. A case of Antley-Bixler syndrome caused by compound heterozygous mutations of the cytochrome P450 oxidoreductase gene. Eur J Pediatr. 2009;168:877-80.

24. Sahakitrungruang T, Huang N, Tee MK, Agrawal V, Russell WE, Crock $P$, et al. Clinical, genetic, and enzymatic characterization of P450 oxidoreductase deficiency in four patients. J Clin Endocrinol Metab. 2009;94:4992-5000.

25. Adachi M, Tachibana K, Asakura Y, Yamamoto T, Hanaki K, Oka A. Compound heterozygous mutations of cytochrome P450 oxidoreductase gene (POR) in two patients with Antley-Bixler syndrome. Am J Med Genet A. 2004;128:333-9.

26. New Ml. Nonclassical congenital adrenal hyperplasia and the polycystic ovarian syndrome. Ann NY Acad Sci. 1993;687:193-205.

27. Rosa S, Duff C, Meyer M, Lang-Muritano M, Balercia G, Boscaro $M$, et al. P450c17 deficiency: clinical and molecular characterization of six patients. J Clin Endocrinol Metab. 2007;92:1000-7.

28. Shima M, Tanae A, Miki K, Katsumata N, Matsumoto S, Nakajima $S$, et al. Mechanism for the development of ovarian cysts in patients with congenital lipoid adrenal hyperplasia. Eur J Endocrinol. 2000;142:274-9. 
29. Belgorosky A, Pepe C, Marino R, Guercio G, Saraco N, Vaiani E, et al. Hypothalamic-pituitary-ovarian axis during infancy, early and late prepuberty in an aromatase-deficient girl who is a compound heterozygote for two new point mutations of the CYP19 gene. J Clin Endocrinol Metab. 2003;88:5127-31.

30. Fukami M, Horikawa R, Nagai T, Tanaka T, NaikiY, Sato N, et al. Cytochrome P450 oxidoreductase gene mutations and Antley-Bixler syndrome with abnormal genitalia and/or impaired steroidogenesis: molecular and clinical studies in 10 patients. J Clin Endocrinol Metab. 2005;90:414-26.

31. Grondahl C, Hansen TH, Marky-Nielsen K, Ottesen JL, Hyttel P. Human oocyte maturation in vitro is stimulated by meiosis-activating sterol. Hum Reprod. 2000;15(Suppl 5):3-10. 